\title{
Analgesic Activity of 6-(p-Chlorophenyl)-4-Substituted-Benzylidene tetrahydropyridazin-3(2H)-One
}

\author{
Mohammad Asif ${ }^{1 *}$ and Mohd Imran ${ }^{2}$ \\ ${ }^{1}$ Department of Pharmaceutical Chemistry, Himalayan Institute of Pharmacy Research, Dehradun, India \\ ${ }^{2}$ Department of Pharmaceutical Chemistry, Faculty of Pharmacy, Northern Border University, Rafha, Saudi Arabia \\ *Corresponding Author: Mohammad Asif, Department of Pharmaceutical chemistry, Himalayan Institute of Pharmacy Research, \\ Dehradun, India.
}

Received: March 22, 2019; Published: May 07, 2019

DOI: $10.31080 /$ ASPS.2019.03.0275

\begin{abstract}
Several studies have been focused on pyridazinone derivatives for design and developing potent and safer non-steroidal antiinflammatory drugs (NSAIDs). So, our interest has been focused on the synthesis and biological evaluation of some 6-(p-chlorophenyl)4 -substitutedpyridazin-3(2H)-one compounds (IIIA-IIIC) as an analgesic agents. These three title compounds IIIA-IIIC were synthesized from 6-(p-chlorophenyl)-pyridazin-3(2H)-one (II). These title compounds IIIA-IIIC were characterized on the basis of IR and ${ }^{1} \mathrm{HNMR}$ spectral data analysis. The title compounds IIIA-IIIC were exhibited significant $(\mathrm{p}<0.001)$ analgesic activity compare to control group by using radiant heat-induced pain test model and acetyl salicylic acid (Aspirin, $100 \mathrm{mg} / \mathrm{kg}$ ) was used as reference drug.

Keywords: Pyridazinone; Analgesic; Aspirin; Spectral Data
\end{abstract}

\section{Introduction}

The well recognized therapeutic utilization of non-steroidal anti-inflammatory drugs (NSAIDs) is valuable in the cure of pain, inflammation and fever. However, long lasting usages of NSAIDs are causes numerous undesirable effects together with gastrointestinal, kidney and hepato-toxicities. Therefore, the innovation of novel, potent and safer NSAIDs is a demanding object for researchers.

Lots of potent drugs are derived from synthetic as well as natural sources; usually in practice have nitrogen atom in the heterocyclic ring system. In recent years various 6-substituted pyridazinones have been reported to possess antimicrobial, analgesic, anti-inflammatory, antipyretic, antiplatelet, antifeedant, herbicidal, anticancer, anticonvulsant, antihypertensive and other anticipated properties [1-5]. On the other hand, the results of the pharmacological test indicated that some considerable figure of substituted pyridazinone compounds possess good nonnarcotic analgesic properties [6-20]. Stimulated by these above findings, our concentration have been focused on the synthesis of some 6-(p-chlorophenyl)-4-substitutedpyridazin-3(2H)-one com- pounds (IIIA-IIIC) which are anticipated to show potent analgesic activities by using radiant heat-induced pain test model.

\section{Materials and Method}

Chemistry

All chemicals were procured from Merk and Central Drug House (P) Ltd., India of laboratory grade for synthesis of title compounds. Melting points (M.P.) of the synthesized compounds were recorded in open capillary tube in liquid paraffin bath as well as in melting point apparatus and are uncorrected. Percentage yields were recorded accordingly (Table 1). Solvent system used during the experimental work for running thin layer chromatography (TLC) plates was toluene, ethyl acetate and formic acid (TEF) in the ratio of 5:4:1 and another solvent system also used was benzene and acetone in the ratio of $4: 1$. IR spectra were recorded by using KBr pellet technique on Perkin Elmer 337 IR spectrophotometer. ${ }^{1} \mathrm{HNMR}$ spectra were recorded in deuterated chloroform using tetra methyl silane (TMS) as an internal reference standard on BRUKER AVANCE II 400 NMR spectrometer. 


\begin{tabular}{|l|c|c|c|c|c|c|}
\hline \multirow{2}{*}{$\begin{array}{l}\text { Nompd. } \\
\text { No. }\end{array}$} & $\mathbf{1 0}$ & $\mathbf{2 0}$ & $\mathbf{3 0}$ & $\mathbf{6 0}$ & $\mathbf{9 0}$ & $\mathbf{1 2 0}$ \\
\cline { 2 - 7 } Control & $3.42 \pm 0.03$ & $3.48 \pm 0.02$ & $3.64 \pm 0.04$ & $3.50 \pm 0.03$ & $3.76 \pm 0.04$ & $3.64 \pm 0.05$ \\
\hline IIIA & $3.51 \pm 0.02$ & $4.73 \pm 0.01$ & $6.62 \pm 0.02$ & $9.24 \pm 0.01$ & $10.56 \pm 0.01$ & $11.92 \pm 0.01$ \\
\hline IIIB & $4.10 \pm 0.01$ & $5.22 \pm 0.01$ & $7.00 \pm 0.01$ & $9.62 \pm 0.01$ & $10.30 \pm 0.01$ & $12.26 \pm 0.01$ \\
\hline IIIC & $3.84 \pm 0.01$ & $4.65 \pm 0.01$ & $5.88 \pm 0.01$ & $8.24 \pm 0.01$ & $9.98 \pm 0.01$ & $10.84 \pm 0.01$ \\
\hline Aspirin & $8.24 \pm 0.01$ & $10.54 \pm 0.01$ & $11.37 \pm 0.01$ & $11.61 \pm 0.01$ & $12.53 \pm 0.01$ & $12.88 \pm 0.01$ \\
\hline
\end{tabular}

Table 1: Analgesic activity of the synthesized pyridazinone compounds (IIIA-IIIC). All results are significantly different from control at $a p<0.001$.

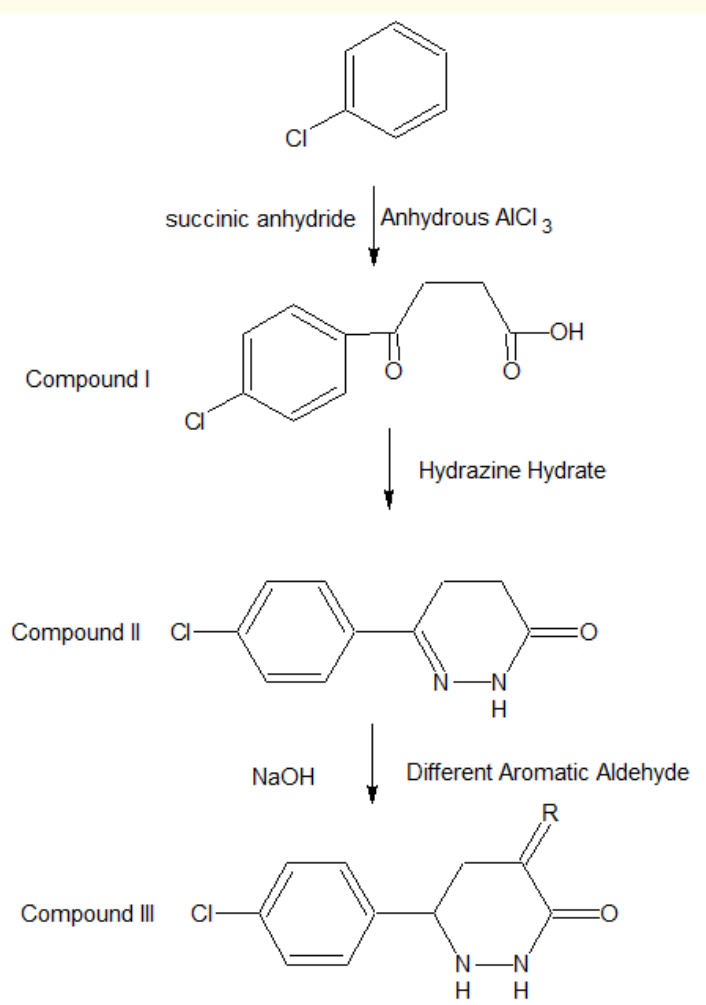

$\mathbf{R}=\mathrm{C}_{6} \mathrm{H}_{5}, \mathrm{C}_{6} \mathrm{H}_{4} \mathrm{Cl}_{1} \mathrm{C}_{6} \mathrm{H}_{4} \mathrm{OCH}_{3}$

Scheme I

\section{Synthesis of 4-Chloro benzoyl propanoic acid (I)}

A mixture of chlorobenzene $(30 \mathrm{ml})$ and anhydrous aluminium chloride $(0.15 \mathrm{~mol})$ was taken in flask and refluxed under anhydrous condition, followed by addition of succinic anhydride in small quantity $(0.10 \mathrm{~mol})$ with continuous stirring [12,21]. The stirring and heating were continued for 5 hrs. The reaction starts immediately $\mathrm{HCl}$ gas is evolved. After this the reaction mixture is leaving over night the contents were poured into ice cold hydrochloric acid $(2.5 \% \mathrm{v} / \mathrm{v})$ followed by steam distillation. The aqueous solution was concentrated to small volume to obtain crude compound and purified by dissolving the $5 \% \mathrm{w} / \mathrm{v}$ of sodium bicarbonate solution followed by extraction with chloroform. The aqueous layer on acidification with dilute hydrochloric acid gave $\beta$-chlorobenzoyl propionic acid and re-crystallized with aqueous ethanol. Melting point: $1200 \mathrm{C}$, yield $70 \% \mathrm{R}_{\mathrm{f}}$ value 0.77 , molecular formula $\mathrm{C}_{10} \mathrm{H}_{10} \mathrm{O}_{3}$, molecular weight178.18. IR Spectra: $3250 \mathrm{~cm}^{-1}$ $(\mathrm{OH}), 1720 \mathrm{~cm}^{-1}(\mathrm{C}=0)$.NMR Spectra: ${ }^{1} \mathrm{HNMR}\left(\mathrm{CDCL}_{3}\right) \mathrm{ppm} 2.82(2 \mathrm{H}$, t, $\left.\mathrm{CH}_{2}\right), 3.32\left(2 \mathrm{H}, \mathrm{t}, \mathrm{CH}_{2}\right), 7.74\left(\mathrm{CH}_{2}, \mathrm{~m}, \mathrm{H}-3,5\right), 7.79(2 \mathrm{H}, \mathrm{m}, \mathrm{H}-2,6)$.

Synthesis of 6-chlorophenyl-4,5-dihydro pyridazin-3(2H)one (II)

The $\beta$-p-chlorobenzoyl propionic acid (I) (0.01 mol) was refluxed for $6 \mathrm{hr}$ with hydrazine hydrate $(0.01 \mathrm{~mol})$ in methanol $(10$ $\mathrm{ml}$ ) containing sodium acetate (50 mg). The contents was concentrated and poured into ice cold water to get 6-chlorophenyl-4,5dihydro pyridazin-3 $(2 \mathrm{H})$-one and recrystrallized with ethanol $[1,4,12]$. Yield $52 \%$, melting point. $140^{\circ} \mathrm{C}, \mathrm{R}_{\mathrm{f}}$ value 0.65 , molecular formula $\mathrm{C}_{10} \mathrm{H}_{8} \mathrm{NOCl}$, molecular weight 193.2. IR $\left(\mathrm{cm}^{-1}\right)$ 1685(C=0), $3100(\mathrm{CH}), 3550(\mathrm{NH})$.

General synthesis of 6-(p-chlorophenyl)-4-benzylidine/substituted benzylidine tetrahydro pyridazin-3(2H)-ones (IIIAIIIB)

A mixture of compound II ( $0.005 \mathrm{~mol})$ and different aldehyde $(0.005 \mathrm{~mol})$ in ethanol $(20 \mathrm{ml})$ and ethanolic sodium ethoxide solution was added and the reaction mixture was left overnight, diluted with water and rendered just acidic with hydrochloric acid [22]. The solid 6-(p-chlorophenyl)-4-benzylidine/substituted benzylidine tetrahydro pyridazin-3(2H)-ones (IIIA-IIIB) thus obtained, filtered and recrystallized with ethanol. 
Synthesis of 6-(p-chlorophenyl)-4-(benzylidene)-tetrahydro pyridazin-3-one (IIIA)

IR (KBr) in cm ${ }^{-1}: 3402$ (Ar-H), 3435 (NH), 2831 (C-H), 1602.56 $(-\mathrm{C}=\mathrm{C}), 1255.3(\mathrm{C}-\mathrm{N}) .1 \mathrm{H}-\mathrm{NMR}(\mathrm{CDCl} 3, \delta$ in ppm): ppm $8.688(1 \mathrm{H}, \mathrm{s}$, $\mathrm{NH}), 5.25(1 \mathrm{H}, \mathrm{s}, \mathrm{CH}), 7.25-7.47$ (CH, m, ArH), $3.924(1 \mathrm{H}, \mathrm{t}, \mathrm{CH}), 1.26$ $\left(2 \mathrm{H}, \mathrm{d}, \mathrm{CH}_{2}\right), 8.86(1 \mathrm{H}, \mathrm{s}, \mathrm{NH})$.

Synthesis of 6-(p-chlorophenyl)-4(p-methoxybenzylidene)tetrahydropyridazin-3(2H)-one (IIIB)

IR (KBr) in $\mathrm{cm}^{-1}: 3402$ (Ar-H), $3435(\mathrm{NH}), 2831(\mathrm{C}-\mathrm{H}), 1602.56$ $(\mathrm{C}=\mathrm{C}), 1509.99\left(\mathrm{C}-\mathrm{O}-\mathrm{CH}_{3}\right), 1255.32(\mathrm{C}-\mathrm{N}), 1166.72\left(\mathrm{OCH}_{3}\right) .1 \mathrm{H}-$ NMR $\left(\mathrm{CDCl}_{3}, \delta\right.$ in ppm): $9.779(1 \mathrm{H}, \mathrm{s}, \mathrm{NH}), 8.491(1 \mathrm{H}, \mathrm{s}, \mathrm{CH}), 6.886-$ 7.7.67 (CH, m, ArH), 3.809 (1H, t, CH), $2.495\left(2 \mathrm{H}, \mathrm{d}, \mathrm{CH}_{2}\right), 3.051(3 \mathrm{H}$, $\left.\mathrm{s}, \mathrm{OCH}_{3}\right), 2.064(1 \mathrm{H}, \mathrm{s}, \mathrm{NH})$.

Synthesis of 6-(p-chlorophenyl)-4-(4-cholorobenzylidene)tetrahydropyridazin-3-one (IIIC)

IR (KBr) in cm-1: $3400(\mathrm{Ar}-\mathrm{H}), 3444(\mathrm{NH}), 2857$ (C-H), 1602.56 $(\mathrm{C}=\mathrm{C}), 1489.79$ (C-Cl), 1292.07 (C-N). $1 \mathrm{H}-\mathrm{NMR}\left(\mathrm{CDCl}_{3}, \delta\right.$ in ppm): 4.689 (1H, t, CH), 8.625 (1H, s, NH), 7.803 (1H, s, CH), 7.455-7.783 (CH, m, ArH), 2.048-2.002 (2H, d, $\left.\mathrm{CH}_{2}\right), 1.441(1 \mathrm{H}, \mathrm{s}, \mathrm{NH})$.

Preparation of test samples for bioassay

Test compounds $(100 \mathrm{mg} / \mathrm{kg})$ were suspended in distilled water and $0.5 \%$ sodium carboxyl methylcellulose (CMC) and were given intraperitonealy (i.p) to the test animals. The animals of the control group received the same experimental handling except that the drug treatment was substituted with suitable quantity of the vehicle. Aspirin in $0.5 \%$ CMC $(100 \mathrm{mg} / \mathrm{kg})$ for analgesic activity was used as reference drug.

\section{Experimental animals}

Male albino mice (30-35 g) were used for analgesic activity. All of the animals were left for 2 days in the laboratory for acclimatization before the experiment, and on the last day they were given water only. Minimum of 5 animals were used in each group. All pharmacological activities were carried out as per Committee for the Purpose of Control and Supervision of Experiments on Animals norms (Regn No: 1145/a/07/CPCSEA), after obtaining the approval from the Institutional Animal Ethics Committee of Department of Pharmacy, GRD(PG)IMT, Dehradun, India.

\section{Analgesic activity by Eddy's hot plate method}

In this method, heat is used as a source of pain. Animals were alone placed on the hot plate maintain at stable temperature $\left(55^{\circ} \mathrm{C}\right)$ and the reaction of animals, such as paw licking or jump reaction was taken as the end response. Analgesic compounds increases the reaction time. The method was first described by Eddy \& Leimbach (A cut off period of $15 \mathrm{sec}$ is observed to avoid damage to the paw). Administration of the control, standard and test compounds to animals by i.p route and note the reaction of time of animals at 10,20 , $30,60,90,120$ min interval on the hot plate after drug administration. A group of albino mice were treated i.p with a dose of $100 \mathrm{mg} /$ $\mathrm{kg}$ body weight with aqueous suspension in 0.5\% CMC Na of the synthesized compounds. In this method, techno heated plat analgesic apparatus was used. The standard drug Aspirin $(50 \mathrm{mg} / \mathrm{kg}$ ) was used reference drug for comparison. The result was tabulated in table 1 [23].

\section{Statistical analysis}

Results were expressed as means \pm S.E.M. Statistical significance was analysed using the one-way analysis of variance followed by Tukey's Multiple Comparison Test where $\mathrm{p}<0.05$ was accepted to be a significant difference.

\section{Results and Discussion}

All the 6-(p-chlorophenyl)-4substituted-4,5-dihydropyridazin$3(2 \mathrm{H})$-one derivatives (IIIA-IIIC) were synthesized from $6-(\mathrm{p}$ chlorophenyl)-4,5-dihydro pyridazin-3-one (II) by reaction with substituted aldehydes. Friedal craft acylation of benzene yield $\beta$-chlorobenzoyl propionic acid (I). Compound I was cyclized with hydrazine hydrate to form compound (II). All the compounds were characterized on the basis of IR and ${ }^{1} \mathrm{HNMR}$ spectral data. IR spectrum showed the characteristics bond at 1700, 1352, 3450, and $1580 \mathrm{~cm}^{-1}$ authenticated the presence of $\mathrm{C}=\mathrm{O}, \mathrm{NO}_{2}, \mathrm{NH}$ and $\mathrm{C}=\mathrm{C}$ groups. The ${ }^{1} \mathrm{HNMR}$ spectrum showed the signal in the form of triplet near $\delta=2.8$ for $\mathrm{CH}_{2}$ protons at 5-position, another triplet is observed at about $\delta=3.0$ for $\mathrm{CH}_{2}$ at 4 position. Aromatic proton also observed in the aromatic region ranging from $\delta=7.0-8.0$. Presence of other substitutes also authenticated in the IR and 1HNMR spectra at the assigned value. All tested compounds exhibited analgesic activities (Table 1) that lasted for 120 minutes and the potency increased with time. All these three compounds are showed significant $(\mathrm{p}<0.001)$ analgesic activity when compare to control group. The most potent compound was (IIIA), all the three compounds were less potent than reference drug aspirin, but compound IIIC was less potent among all compounds. The degree of potency in ascending order is IIIA>, IIIB>, IIIC.

Analgesic activity is commonly possessed by inhibiting the synthesis of cyclooxygenase (COX) or prostaglandin (PGs) [19]. These PGs cause or responsible for stimulus of pain receptors and sensitize the skin to painful stimuli possibly because they sensitize 
pain receptors to mechanical and chemical stimulus like the pain producing effect of mediators (e.g. histamine, kinins) which are released in tissue injury and inflammation. Inhibition of PGs synthesis may account for the analgesic activity of the title compounds. Pain and inflammation is linked with numerous patho- physiologies of various clinical conditions like arthritis, cancer, tissue injury and vascular diseases. Pain induced by thermal stimulus of the hot plate is specific for centrally mediated nociception and the analgesic effect of the NSAIDs has also been credited to effects at peripheral or central neurons [24-26].

In the conclusion, synthesized 4-substituted-6-(pchlorophenyl)-4,5-dihydropyridazin(2H)-3-one (IIIA-IIIB) derivatives have proven that analgesic activities. These compounds were less effective than standard drug Aspirin. Various different substituted pyridazinone compounds are aimed at studying for their contribution to analgesic and other pharmacological activities.

\section{Acknowledgement}

The authors are thankful to GRD (PG) IMT, Dehradun, India, Department of Pharmaceutical chemistry, Himalayan Institute of Pharmacy Research, Dehradun, India, Department of Pharmaceutical Chemistry, Faculty of Pharmacy, Northern Border University, Rafha, Saudi Arabia as well as to SAIF, Punjab University, Chandigarh, India for providing financial as well as technical support and facilities to carry out this work.

\section{Bibliography}

1. Mojahidul I., et al. "Synthesis and antimicrobial activity of some novel oxadiazole derivatives". Acta Poloniae Pharmaceutica 65.3 (2008): 353-362.

2. Sukuroglu M., et al. Arzneimittelforschung 56 (2006): 337345.

3. Sukuroglu M., et al. Archives of Pharmacal Research 28.5 (2005): 509-517.

4. Siddiqui AA., et al. "Synthesis and antiinflammatory activity of 6-(substituted aryl)-2,3,4,5-tetrahydro-3-thiopyridazinones". Indian Journal of Hetrocyclic Chemistry 13 (2004): 257-260.

5. Banoglu E., et al. "Synthesis of 1,5-diarylpyrazol-3-propanoic acids towards inhibition of cyclooxygenase-1/2 activity and 5-lipoxygenase-mediated LTB4 formation". Arzneimittelforschung 55.9 (2005): 520-527.

6. Gokce M., et al. "Synthesis of new Mannich bases of arylpyridazinones as analgesic and anti-inflammatory agents". Arzneimittelforschung 55.6 (2005): 318-325.
7. Sahina MF., et al. "Synthesis and Analgesic and Antiinflammatory Activity of Methyl 6-Substituted-3(2H)-pyridazinone-2ylacetate Derivatives". Arch Pharm (Weinheim) 337 (2004): 445-452.

8. Okcelik B., et al. Arch Pharm (Weinheim) 336.9 (2003): 406412.

9. Giovannoni MP., et al. Journal of Medicinal Chemistry 46 (2003): 1055-1059.

10. Chintakunta VK., et al. "3-0-substituted benzyl pyridazinone derivatives as COX inhibitors”. European Journal of Medicinal Chemistry 37.4 (2002): 339-347.

11. Gokçe M., et al. "Synthesis and antinociceptive activity of 6-substituted-3-pyridazinone derivatives". Farmaco (Societa Chimica Italiana) 56 (2001): 233-237.

12. Khan MSY and Siddiqui AA. Indian Journal of Chemistry 39B (2000): 614-619.

13. Dogruer DS., et al. Arch Pharm (Weinheim). 333.4 (2000): 7986.

14. Piaz VD., et al. European Journal of Medicinal Chemistry 31 (1996): 65-70.

15. Hallas J., et al. Scandinavian Journal of Gastroenterology 30 (1995): 438-444.

16. Flouzat C., et al. Journal of Medicinal Chemistry 36.4 (1993): 497-503.

17. Rubat C., et al. "Synthesis of Mannich bases of arylidenepyridazinones as analgesic agents". Journal of Pharmaceutical Sciences 81 (1992): 1084-1087.

18. Rubat C., et al. "Synthesis and pharmacological evaluation of $\mathrm{N}$-substituted 4,6-diaryl-3-pyridazinones as analgesic, antiinflammatory and antipyretic agents". Chemical and Pharmaceutical Bulletin (Tokyo) 37.10 (1989): 2832-2835.

19. Santagati NA., et al. 40.12(1985): 921-9.

20. Takaya M., et al. Journal of Medicinal Chemistry 22.1 (1979): 53-58.

21. Furnish BS., et al. "Vogel's textbook of practical organic chemistry 5th edition". tatchell longeman group Ltd. London, (1989): 695.

22. Aly AA, Wasfy AAF. Indian Journal of Chemistry-B, 43B (2004): 629-635. 
Analgesic Activity of 6-(p-Chlorophenyl)-4-Substituted-Benzylidene tetrahydropyridazin-3(2H)-One

23. Kulkarni SK. Handbook of experimental pharmacology 3rd edition vallabh publication New Delhi (1999): 131-133.

24. Van JR and Botting RM. "New insights into the mode of action of antiinflammatory drugs". Inflammation Research 44 (1995): 1-10.

25. Raskin JB. "Gastrointestinal effects of nonsteroidal antiinflammatory therapy". The American Journal of Medicine 106.5B (1999): 3S-12S.

26. McCarthy D. "Nonsteroidal antiin flammatory drug-related gastrointestinal toxicity: definition and epidemiology". The American Journal of Medicine 105.5A (1998): 3S-9S.

\section{Volume 3 Issue 6 June 2019}

(c) All rights are reserved by Mohammad Asif and

\section{Mohd Imran.}

